\title{
'Co-Emergence' In Ecological Continuum: Educating Democratic Capacities Through Posthumanism as Praxis
}

Aiden Sisler (Technische Universität Berlin)

\section{Becoming and Beyond: Co-Emergence in Complex Ecologies}

In many senses, we are already posthuman (see: Hayles 1999; Nichols 1988). While humans today have surpassed the boundaries of former eras of human beings, the types and forms of posthuman we shall yet become are more or less open for authorship as too are the ecologies within which we will either co-emerge, or perish. The time of the Anthropocene ${ }^{1}$ and the "modernising rush" of Globalisation (see: Docherty 2011) pose supreme challenges to out global response to issues of climate change, governance, and scale 2 , just as our computational technologies approach singularity or, at the very least, unparalleled accelerating power (see: Eden, Moor, Søraker, \& Steinhart 2012). By certain bio-political accounts, our very human barriers have been breached, thereby contesting long-held dualistic notions (e.g., mind/body, natural/cultural or artificial, part/whole, independence/ dependence, etc.), in favour of analysing dialectics, dichotomies, and the spaces between and within $^{3}$. Onto-epistemological conceptions of the co-emergence ${ }^{4}$ and reciprocal influence of beings within complex ecological systems' development de-centres humans in their environments, whilst recognizing their criticality in yielding significant environmental impact. Moreover, the epistemological scale continuum (see: Manson 2008 and his contribution on scale epistemologies and recommendations for effective human-environment research), ranging from realist logical positivistism's tenets of the independence of natural scales to social constructivists' privileging of

1 Paul Crutzen, the term's inventor, defined our epoch of overwhelming human influence on the global ecosystem.

2 See: Buizer, Arts, \& Kok (2011) depiction of the interdependency of scale (complex cross-level dynamics) and governance (policy development and implementation based on dialogue and cooperation among scientists, policy makers, and citizens) issues in environmental concerns.

${ }^{3}$ Asberg (2013) succinctly sums up posthumanism as an ethical turn.

${ }^{4}$ Flender (2011) elaborates: adaptation "as a mode of being-in-the-world ... best conceptualized as a dynamically co-emerging whole prior to any mind-body and selfother distinction". 
subjectivity and plurality, all contribute to fuller depictions of biocomplexity in human-environment ecological systems, paving way for intra- and interdisciplinary global and local dialoguing and solutions.

Furthermore, posthumanism studies, meaning here, as per Ferrando $(2012,9)^{5}$, a praxis which challenges anthropocentric humanism, inviting critical "inquiry to non-human life: from animals to artificial intelligence, from aliens, to other hypothetical entities" and their networked relations, offer up unparalleled opportunities for exploring desirable ethical systems in applied philosophy and politics. Contrary to anti-humanism, posthumanism's potential lies in its continuance and extension of Enlightenment and humanist ideals, such as freedom, agency, equality, justice, care and prevention of harm, while acknowledging the ecological continuum and its diversity of complex ecosystems of which humans, animals, organic, and inorganic materials are all part. Consequently, the practice of posthumanism and its ethical implications entail co-construction and co-emergence of moral philosophies and related environmental ethics (for more on the growing field of environmental ethics see: Dereniowska \& Matzke 2014) for survival and inclusive flourishing. In the following, I sketch out an exposition on fostering inclusive participatory dialogue within complex systems, so as to show posthumanism's import to ecologically-based applied ethics.

Development of moral democratic capacities through participatory practices - by doing it and being embedded within it - are harmonious with Dewey's (1916) educative philosophical notions of civic engagement (Starrat 2009). Through the infusion and deepening of egalitarian relations among individuals in the structure of everyday life, particularly in educational settings, moral competencies ${ }^{6}$ of political beings (as organization across levels is intrinsic in ecology and therefore hierarchical arrangements must be acknowledged as such, see: Holling 2004) can take root, nurturing skills for empowerment and participation. It is a truism worth repeating that simply reading about classical and humanist ethical ideals and free and unrestrained discussion is wholly insufficient, and even counter-productive.

Our current ecological challenges and global crises highlight the need for democratic skills to adapt to increasingly complex and shifting socioecological systems. Roughly a century ago, Dewey envisioned "a mode of associated living"7 and full participation through conjoint "communicated experience" whereby socio-emotional learning grows in tandem with pragmatic deliberative moral reasoning ability (see: Lind 2011a, for more on

\footnotetext{
5 Ferrando delineates posthumanism-based methods and epistemology relations to "environmentalism, deep ecology, animal rights and roboethics" and the anthropocentric nature of its visioning as it is created by humans themselves.

${ }^{6}$ See Georg Lind's corpus of work on moral competence and judgment.

7 Here I would add "in our evolving materializing ecosystems".
} 
moral competence and Kohlbergian moral judgments). The vision of collaborative ethical development remains unfulfilled.

As a reappraisal of democracy's relation to anthropocentric humanist canons, posthumanism calls for power, ruling (-kratia), and privilege to be examined, negotiated, and extended along an ecological continuum. One further sees the essential of providing fertile conditions for a program of inclusive inquiry and "agentic-related thinking" including free participation, tolerance of multiple perspectives, and open non-coercive communication, as systemic ways of relating are echoed and re-produced, or, in alterity, contested, reformulated, and, potentially transcended. In such a way, ethical systems and their constituents (i.e., moral reasoning, values, affects) are directly and indirectly communicated through education and other formal and informal modes of social relations and their dynamic rooted interplay ${ }^{8}$. Indeed, emergence of phenomena, (e.g., entirely new ways of relating) are deemed possible in the affirmative generative capacity (Braidotti 2013) of exploring the multifaceted nature of ecological relations over time (e.g., student-teacher, cell-scientist, consumer-consumed, dismembered animal part-microscope, and so on). By specifically inquiring into what it is that makes us human - normative assumptions of "mankind"'s nature, natural order, the feral and the "cultured", etc. - while other life forms are considered non-human, and the inter-reliance of organic and inorganic matter in a global ecosystem, we can analyze how social constructions and ecological assessments bring our co-evolution to bear. All the more, sites of contestation and tension in dialectical analyses preserve the plurality of accounts yet still recognize the ecological groundings and plinth of historical and empirical insight. It requires no further elaboration that the barriers here are great and many, though with widening of the discursive field, inclusive, though at times immensely difficult, discussions can bear emergent fruit, barren of the sanitizing rhetoric of "social justice", or as Bloom $(1975,662)$ intones, "A First Philosophy for the Last Man".

Complexity and systems perspectives paired with integrative pluralism approaches complement these aims toward actualizing posthumanism's ethics and ethical praxis in the socio-cultural, aesthetic, scientific, and moral materials of not-yet-rendered non-anthropocentric ecosystems. A posthumanism-based examination of the political encompasses the full ecological continuum and all its often-ambiguous holoarchic ecologies, materials, and emergent phenomena while retaining the pragmatic moral discussions of ethical progress. It further implicates intergenerational environmental justice and principled considerations through its diachronic analyses, examining how things change over time. Finally, through sourcing and speaking directly to entities' diversity allows for a more refined and

${ }^{8}$ See the classic agency-structure paradigm, e.g. Bourdieu's notion of habitus. 
nuanced recognition of the right to a dignified life, akin to a capacitiesapproach ${ }^{9}$, toward peaceable dynamic co-existence.

In addition, I wish to identify areas in which to carry out posthumanism in complex ecologies, as both a processual means and ends toward direct participative deliberative democracy ${ }^{10}$, and some of the original professed ideals of humanistic and Enlightenment traditions ${ }^{11}$. I will draw attention to the potential of posthumanistic thought, and highlight ways to work with and embrace divergences of contemplation, perspective, and ecological history in evolving systems.

In so doing, reflections of what it means to be human - or not - and the accordant rights granted or withheld therein, are argued to be valid and representative if addressed in The Ecological Commons through analysis of instrumental and intrinsic valuation of our environment's "horizontalizing"12 or, flat ontologies (Morton 2012), of which posthumanism prescribes and requires. That is, I make the normative claim that what we as individual moral agents should or ought to do, what is right or wrong, what is preferred, and what is to be, or worthy of being, supported and pursued can in fact ultimately and continually be determined in processes of posthumanistic inclusive democratic and co-determined praxis ${ }^{13}$. Furthermore, our co-evolved and emergent moralities ought to be iteratively examined and developed through such means, while, irrespective of intentional efforts or otherwise (e.g., entropic apathy, lack of engagement due to inaccessibility or resources), our conjoined though distinctively manifested destinies - either co-constructed collaborative, or complicit, constrained and enforced - will be determined and rendered material in the flow of space-time. As such, posthumanism, in practice may reveal certain emergent properties as conceptualized in

\footnotetext{
${ }^{9}$ See Sen and Nussbaum for more on development and the capabilities approach.

${ }^{10}$ Democracy as meant here is taken not to be the form of limited civic engagement by oligarchic (Gilens \& Page 2014), parliamentary, or so-called representative democratic rule currently masquerading as 'demos' 'kratia' (rule by the people) across the dominant Northern/Western world paradigm (see: Fishkin 2009, for alternative "bridging" models of democratic participation).

11 Carey Wolfe's (2010) depiction of posthumanism does not discount the aims of securing dignity and rights of all human beings. Rather, Wolfe draws out a desire to recover and reclaim the human in contrast to "Promethean" transhumanist images. This aware human is open to its "embodiment, embeddeddness, and materiality, and how these in turn shape and are shaped by consciousness, mind, and so on. ... It allows us to pay proper attention to... the material, embodied, and evolutionary nature of intelligence and cognition" (Wolfe 2010, 120).

${ }^{12} \mathrm{~A}$ term coined by Laurence Currie-Clark.

13 I use total here insofar as it is worthwhile outlining a "saturated" participatory process of discourse as an ultimate goal for structural strength through diversity while retaining pragmatic efficacy (Asberg 2013 outlines this potential ethical turn in posthuman, material, and ontological theory).
} 
integrative pluralism (Mitchell 2004) and emergent evolutionism ${ }^{14}$ in making the nature of symbolic and embodied interactions and intercommunications of a systemic whole more or less identifiable or at least, experienced, observed, and discussed in examining the dialectics gap between Ideals and the actual, between the potentiality and actuality of, what Aristotle termed, the entelechy ${ }^{15}$ or whole.

If one could amend this assertion of the continued evolving effort toward determining, creating, and enacting ideals, morals, virtuous behaviour, and so on, of the vital democratic variety, certainly, posthumanism's emphasis on the awareness and inclusion of ecological continuums needs be acknowledged. For, as Sayer (2011 148) brings to attention, "diversity of cultural $^{16}$ (sic.) forms does not disqualify or relativize ethical theory but presents it with more difficult judgments". For this, we as responsible inhabitants of distinct and unified ecologies require contemplative dialogic space for the gradual ${ }^{17}$ development of such capacities.

Next, I outline how we might go about mapping out areas of moralethical inquiry. In regards to full inclusion of interrelated agents along the ecological continuum, it is crucial to ask who is not involved, whose role is it to go about "involving" these non-involved entities. Furthermore, what questions are not being asked, and which pieces are we missing in forming the most effective and equitable solutions? To these ends, Mitchell's (2004) approach of integrative pluralism holds great promise and carries with it the eco-historical cachet necessary for dually compassionate and reasoned understandings of living and non-living entities in ecological systems ${ }^{18}$. There is a case for the unparalleled timeliness of "slowing down", "zooming out", and "tuning in", entering into processes of dialogue for co-construction to which all have the right and responsibility of participation, particularly in light of our continued access to ever-greater perspectives, data, and technologies. Here, integrative pluralistic accounts of complex ecologies or systems constitute an opposite approach to the requirements of our Zeitgeist, with its rapidity and

14 E.g. Samuel Alexander's (1920) supervenience of qualities of "life" and "mind"; universal codes of moral grammar and the moral language they give rise to (Mikhail 2007) though, as Sayer $(2011,119)$ elucidates, "univeralism need not assume uniformity".

15 As in Bhaskar's $(1993,21)$ Dialectic: The Pulse of Freedom: "Hegelian dialectic is the actualized entelechy of the present, comprehended (and so enjoyed) as the end of everything that has led up to it".

${ }^{16} \mathrm{~A}$ desired alternative is: ecological forms.

17 Daniel Kahneman's slow-fast thinking paradigm is of great utility in deliberative examination of moral issues and ethics. In terms of implicit biases against "othered" groups or individuals, deliberative effortful cognitions and reasoning is assistive in balancing these initial (subterranean or explicit) stereotypes and impulses.

${ }^{18}$ In a similar vein of the controversial notions of Leibniz's vis viva and Driesch's vitalism, Samuels writes on the "directing agency" of which is labeled "space-time, the universe in its primordial form, is the stuff out of which all existents are made". 
interconnectivity of anthropocentric Anthropocene-induced change, selfdetermination, and mutual respect of entities within their interlinked communities and systems. The re-called focus upon "the right to rights", as famously propounded by Arendt (1958), of the interwoven material complex of humans, living beings, non-living, and technological entities, and those yet to come, can best be informed by dynamic pluralistic integration in fields of systematic inquiry.

As Wolfe (2010) observes, humanism frequently falls short of its own ideals and strivings for such circular patterns of reasoning in attempting to bestow rights upon so-called human agents. Indeed, the technical delineation and definitions (judicial, legal, etc.) of what it means to be considered, whether legally or non-institutionally recognized, "as human" constitutes a sociohistorical construction, and those who have been deemed sub-human or the like have suffered. Nonetheless, it is the incontrovertible right of entities (I use the term here as an effort to put posthumanistic principles into practice), to have rights such as the right to becoming, to self-creation, to freedom from harm, and so on. Insofar as what we mutually co-construct to mean human will be continually negotiated, the right to life of humans and those for whom contemporary society deems not fully humans (or, relatedly, non-citizens or non-persons) will continue to be fought for ${ }^{19}$. To this point, it is worth mentioning that common rhetorical devices in the carrying out of genocide, or "race-murder" (Hitchens 2007 cites Henry Morgenthau's use of the term) count "de-humanizing" language, euphemisms, and allusions to the "bestiality" or "non-humanness" of targeted groups among their murderous and often highly rational tactics (see: Dutton 2007).

There exist manifold epistemological challenges and ontological problems inherent in the mind attempting to know and think of itself and the other, and to think of its non-consciousness or absence of experience, or even, as in the politics of geo-philosophy (i.e., conservation versus preservation), of a world absent of humans. Such explanatory gaps are further bound up with the difficulties of subjective and objective credibility, with various theoretical insights often pulled together in often dizzying arrays of combinations (e.g., vitalist and New materialism). Complexity research contributes greatly to elucidating areas of the unknown in terms of emergent phenomenon in a systematic ecological manner20. For, as Goldstein (2004 2) highlights, "Whereas elsewhere in science the presence of such knowledge gaps has customarily prompted attempts to close them, in the case of emergence these very knowledge gaps are exactly how emergence is defined and recognized in the first place. That is why emergence has challenged traditional reductionist scientific strategies".

\footnotetext{
${ }^{19}$ For example, Not Dead Yet campaign vs. Peter Singer.

20 See interdisciplinary methods such as agent-based modeling of complex systems.
} 


\section{Co-Emergence Or "Becoming With" Together}

Despite recent calls to bring posthumanistic theorizing into the immediate through education and praxis (see: Snaza et al. 2014; Ferrando 2012), few concrete efforts have followed. Ensuring our survival and actualizing our capacities and potential as non-anthropocentric beings requires deliberative education of the moral democratic variety in particular. There is no requisite in the exclusionary unbalanced combative antagonism of our current modes of scientific, ethical, and moral inquiry. Rather, antagonism (or conflict), sourced and embraced within a dialectical negotiative or solution-seeking, tolerant and multi-perspectival environment, can in fact energize the process of collaborative and compassionate communication and richness of understanding characteristic of democratic ways of living (Lind) (see: Dereniowska, Matzke 2014).

I see this in terms of Haraway's "becoming-with" (2008) or "becoming together" conceptualized by and Snaza and authors (2014) as an interrelated concept likened further to Braidotti's (2013) affirming generative bio-political philosophy of the posthumanist tradition. I group these and the biological scientific and moral philosophical corpus of thought into a developmental "integrative pluralism" complex of the organic and inorganic. This is done with both an intent and an inherent logic: through the integration of all we know, keeping in mind and being open to the spectre of all we cannot, with all of our individually unique and collectively shared experiences, we can embark on a collaborative and reconciliatory ${ }^{21}$ process of crafting out climates and spaces for honing moral competence and, hopefully, emergent deep ecological solutions through democratic discourse and relating.

Mitchell (2004 85) further cautions against both strict reductionism endemic to scientific inquiry and epistemological anarchy, stating, "I find the advocacy of retaining all, possibly inconsistent, theories that emerge from a community of investigators and the insistence that any collection of analyses of the same phenomena must be reduced to a single theory equally unacceptable. How can a set of theories be used collectively to achieve a more complete understanding than any of the theories taken in isolation?".

I argue that by enlisting and encompassing the diversity of experience in and across the multiplicities and interdependencies of various ecologies we can protect against destructive, nihilistic, total merging tendencies, sociocultural homogenising or smudging out of difference, whilst retaining a sense of steadiness and steadfastness to the task at hand. Rather, within an integrative pluralism paradigm, diversity can be viewed as an asset in considering the complexity-stability-diversity interrelationship and necessary adaptive demands conferred on organisms of rapidly shifting ecologies.

${ }^{21}$ Knut Gnustad's working paper, Beyond purifications: exploring conservation and its critique, depicts some of the challenges of addressing colonial impacts on nature and beings in terms of win-win versus "trade-off" approaches. 
Tolerance of ambiguity and non-dogmatic knowing 22 form part of the climatogenic whole of posthumanist sociality yet they additionally then require flexible capacities or abilities to maintain ecological system balance.

Posthumanism problematizes or critically examines transhumanist "superhuman" rhetoric and argumentation. Herein resides posthumanism's generative potential in ecosocio-moral discourse: it provides a space for leveraging the desire to do and become good in the world, for learning to work with, shape, and so too alter our incredibly diverse and adapting nature. And as all material is embedded within a non-oppressive, non-enslaving, asharmonious-as-possible ecosocial continuum, and, breaking from narcissistic Promethian desires, in cultivating compassionate reasoning in a wholly inclusive process.

Posthumanism is not so much about fundamentally changing what it means to be human unlike transhumanist and "ultra-humanist" ideas. Though we are far from grasping the socio-biological programming requirements of beings, human or otherwise, integrative pluralism's tools of empirical inquiry that fold in objective and subjective dialectics, and acknowledgement of their epistemological claims (Manson 2008), assist in shedding light on the limits of reductionist frames via the concepts of causal closure limitations and downward causation (see: Kim 1992). Likewise, the energizing group of developmental systems and complexity ${ }^{23}$ perspectives contribute to a diachronic account, and so, provide a space for conceptualizing how we might go about co-evolving with respect to our shared ecological continuum.

One of the particularly compelling imperatives of actualizing posthumanism, rests in its capacity to craft desired possibilities in mind and matter. Democracy, taken here as communally, non-violently, and respectfully living together (Lind 2011a; Lind 2011b) with different others, encompasses in essence and content, both variegated and common strands running through our combined wisdom of lived experience, scientific and moral advancement. It points toward paths of best practice, of flourishing for the individual and the collective. Such overarching goals or values are embodied in our personal, social, and collective identities, cognitions, emotions, experiences, and behaviours. They ultimately and dynamically arise from and give rise to more or less coherent internally constructed though still negotiable moral schemas or philosophies, which, again recalling Dewey as too Aristotle, are educable, and so, to be freely developed.

Timely re-evaluations of what it means to be human or not, to be a living being within our ecosocial space as currently and pre-emptively defined, and what rights ought to granted such beings, or life in its broadest sense, bring current moral and bio-political tensions to the fore. Such an

22 See Habermas's post-secular society concept for peaceable dialogue and coexistence.

23 See the Santa Fe Institute on Complexity, for instance. 
energetic discourse opens up the possibility for moral deliberation-based relating, regarding ethical issues and applications, including solutions to preserve freedom and protection of life within complex ecologies. In order to determine such ethical solutions, it is necessary to enter into a discourse space in which voices are heard and valued equally. Among previously dampened out perspectives and histories include those for whom posthumanism stands to particularly bring justice: peoples subjugated to oppression, so-called nonconforming individuals, and agents who interlocute between disparate though dynamic socio-cultural worlds, as their border locations place increased strain on negotiating among and between multiplicities of perspective, worldview, moralities, and lines of reasoning.

In continuing Snaza et al. (2014) contention that "posthumanism pushes intersectionality to the point where no one - no matter their field, interest, or position of power - can afford to ignore these critiques" (as in "minoritizing discourses" of: Sedgwick 1990), namely, those human/humancentric theories, I specifically propose one particular discursive space in which to communally enter into such conversations, which will themselves constitute posthumanism in action: moral democratic immersive experiences (see Lind 2011a; b). It is especially within such spaces that we might actively challenge and claim rights for beings and non-living forces within our ecosocial system in its entirety, that we may dispute and turn over versions of the posthuman as apocalyptic or benign, as situated emancipator (see: Baxi 2009 , for more on how posthumanism reflects on the theory and practice of human rights) or as colonizer/settler (Snaza et al. 2014). Moreover, we can begin to apply these political philosophies to the real world in terms of ecological ethics, policy, and practice.

As Asberg writes, "Posthumanist ethics, entangled with ontoepistemologies of world »intra-actions « (Barad), emerge as efforts to respect and meet well with, even extend care to, others while acknowledging that we may not know the other and what the best kind of care would be" $(2013,8)$. In following Japanese philosophical thought on ontological co-emergence of selfother (Arisaka 2001), combined with robust humanist notions of selfhood and Kantian autonomy, this acknowledgement of both the ambiguous interdependence, independence, and co-determination of various agents and materials in our complex biosphere does well in toward equipping us for an evolving multifaceted world. 


\section{Ecological Flourishing and Deep Democracy Through Deliberative Process}

We may take both a naturalistic examination of the way in which individuals and groups come together for peace, collaboration, and synergizing potential, de-escalating the heightened moral affectivity, behind "us-them" constructions of "the other" as "the other" is seen as existing both outside and within the identities of bicultural, transcultural, and so, by way of extension, of trans- and post-humanist beings. Intriguingly, Randrup (2004) further conceptualizes the animal mind from a collective unconscious perspective, a monopsychism mystical concept deeply embedded in manifold world spiritual traditions (e.g., Rastafarian, Averroism) and taken up extensively by Jung (1936). Though some of these concepts may appear New Age-y, posthumanism is not a far-off sensationalistic, phantasmagorical account of hypothetical futures as so often is portrayed in technocratic mass media views of transcendent man. Rather it asserts that deep peace and democracy, a culture of mutual recognition and respect, and of the potential for intimate moralistic encounters with the self through and with encounters with others are woven into the nature of humans and social animals (De Waal 2009). The seeds are there.

Around a third of all people feel deep kinship and are ready to uphold the rights of individuals regardless of their group membership (see: McFarland, Webb, \& Brown 2012). Moreover, individualism and agentic rights are now understood to be not mutually exclusive to collective strivings and the high valuation of relatedness and social relationships is found across cultures ${ }^{24}$. This presents as self-evident in regards to arguments in favour of basic moral sense (Wilson 1993). Certainly, one might see how we can ideally apply and link this and other ways of being human (e.g., egalitarian, moral, altruistic, compassionate personalities and identities, internal codes of principled conduct (Kohlberg 1984)) onto posthumanist values and praxis. Not surprisingly, support for animal rights through arguments spanning from freedom from harm or minimization of suffering to justness of imposing harm upon a being, whether sentient or otherwise, is closely linked up with support for human rights, rationally based upon the aforementioned ethical principles, though highly and necessarily disputed 25 .

Posthumanism as praxis further sets the stage for additional exploration and careful consideration over who and what is worthy of protection and in what circumstances. Terms like "humanimalmachine" are assistive in reformulating our interdependencies and sites of commonality and divergence (Pettman 2011). Humans are indoctrinated into ideas of human exceptionalism (speciesism) and the arbitrary handing out of those rights

\footnotetext{
24 See Kagitcabasi's developmental documentations.

25 Singer vs. Not Dead Yet, for instance.
} 
drafted up by some to be bestowed upon human subjects as natural, and so, just. We see here the circularity of the naturalistic fallacy: that which is seen in nature is good, with the human sitting atop the hierarchy of living beings, invoking evidence of largest neocortical volume to complexity of living arrangement. The human is therefore the greatest evolutionary achievement, and, in line with social Darwinism, western enlightened man is the evolutionary pinnacle of goodness or morality, and so forth.

Likewise, while the over-arching predisposition toward communalism or other egalitarian ideals is inborn though of varying levels, with some exhibiting and holding fast to such values across situational demands is not of prime focus. Rather, such issues are to be disputed in a posthuman moral discourse and discussion on ethical ideals worth striving for and actualizing, and, in following, the focus of technological, political, and biological advancement.

\section{Developmental Systems Perspective}

I previously mentioned combining integrative pluralism in combating reductionism's explanatory shortcomings. Developmental systems perspective (DSP) is a metaphorical model for our co-constitutive process of "becoming-with"26 together (Snaza et al. 2014) in complex ecologies. Explicitly, a reciprocal DSP - integrative pluralistic approach ideally addresses and acknowledges the variety of knowledge claims situated on the epistemological scale continuum of (human)biomass-environment complex interactions (Mason 2008).

As a brief iteration of DSP, it is one among an over-arching metatheoretical framework of the systems approach, which constitutes a means for studying stability and change, transposed from the study of complex and nonlinear systems in physics and maths. Defining qualities of systems theory include the self-organizing capacity of interdependent systems and their interface, which in turn create dynamic representations capable of informing individual agentic and multiple concentric realms of "higher-level" development (Witherington 2007). The advantage of DSPs in particular in democratic actualization of the individual and the whole, is that there is no set normative sketch of development, and that the self-organizing properties of the constituent parts and interlocking systems interact to exert either stabilizing or destabilizing of the greater whole. In terms of ontogenesis, this application focuses upon precepts of systems theory like feedback, interdependent time scales, internal diversity, and nonlinear change in the conceptualization of multistability. What remains to be seen is how large-scale

${ }^{26}$ See Haraway's concept of "sympoeisis". 
DSP conceptualizing and modeling can or cannot be translated to globalized discourses and analyses.

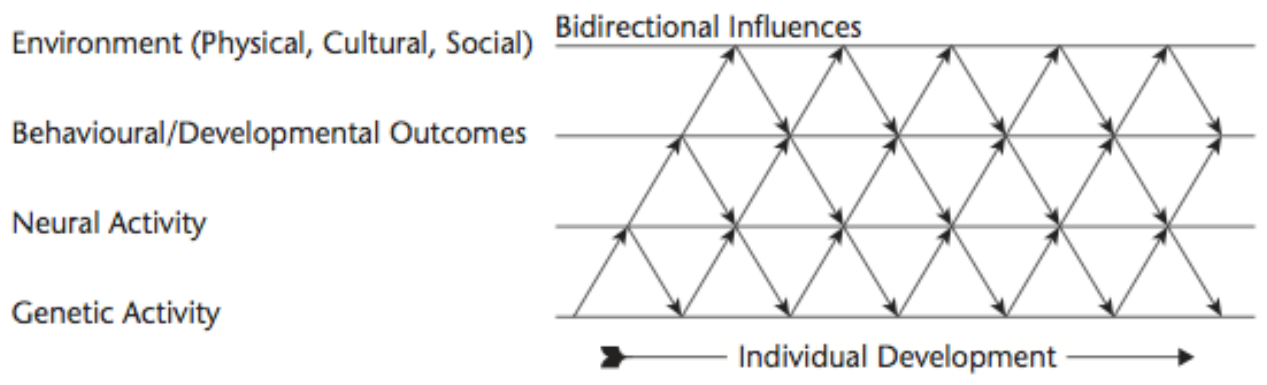

Figure 1. Developmental systems perspective of development depicting bi-directional interaction between and within multiple levels of influence (based on Gottlieb, 1992/2002)

DSP proffers a conceptualization of the development of globalized ecologies of the organic and inorganic which is nonetheless not new, for mysticism and vast swathes of disparate human cultures have converged on similar universal views of the universe and, however contentiously, the moral. This emergentism, or Aristotle's entelechy, continues to bear out the greatest explanatory and generative potential for our ecologies. Other promising perspectives includes: the view that increasing complexity brings greater potential adaptability, progress follows more of a continuum than a distinct leap, ostensive showings of emergent phenomena are continually changing and variegated, and are dynamic in that the complexity of complex systems evolve over time. Additionally, the locus of emergent phenomena occurs at global or macro levels, coherence of the presentation of the integrated whole tends toward uniqueness across time, where such coherence links up "lowerlevel" parts to a "higher-level" unity, and lastly, emergence display features not formerly deducible and observable at the micro-level (Goldstein 1999; e.g., The Black Swan effect - Taleb 2010).

Posthumanism is then to think in one and many systems. It embraces developmental complexity, emergence, and communicative experience beyond oneself. This has held weight in examining intergenerational justice with respect to the ecosystems we pass on to our kin and those to come. As Goldstein (1999 52) states, "when a dynamical system bifurcates, this event signifying both a quantitative and a qualitative metamorphosis...new attractors then dominant the system and thereby allow for the emergence of something radically novel in respect to what came before". In this way, posthumanism's visioning represents both an opportunity to develop and coemerge toward just ecologies and a warning of potential unparalleled global wreckage and catastrophe.

Systems science further destabilizes the discourse of anthropocentric views by prescribing transdisciplinarity as a necessity. If we think of IBM's Big 
Blue multi-level, transdisciplinary cross-institutional partnership, similar arrangements could feasibly attempt to translate complexity modelling along with pluralistic integration of multiple authorships for the composition of ethical posthuman ecosocial systems composition. Such endeavours toward locating and acknowledging the feedback loops (epigenetic phenomena, for example) and influences between all entities, organic and inorganic, is ultimately to shine light on our diversity, interconnectivity, interdependence, and shared and divergent histories. As we are part of a complex dynamic network of interactions, our relationships are not mere aggregations of our individual constituent parts; we can give rise to new ways of being. We can initiate change though our conjoined mobilizations in response to an event: the emergence of environmental conflict resolution and other collective movements have been well-documented and gaining steam (Morrill \& OwenSmith 2002). By collaborating within a moral democratic space, emergent actuating potential transpires, leading to insights and solutions.

\section{Leadership, Governance, and Plato's Drunken Captains}

Who is spearheading the posthumanist discourse? Thus far, a schism exists between those with socio-cultural, political, and educational capital (e.g., corporate representatives, policy makers and imposers, etc.) and the wider public. Extensive and rigorous dialoguing among entities, groups, and individuals is a requisite for sustainable multi-faceted solutions, and tackling governance, scale, and accountability issues head-on (Buizer, Arts, \& Kok 2011). In which space and in what way might the exercising and striving of posthumanist values and the posthuman idealized vision of a most morally desirable synergistic agentic and collective flourishing transpire? A number of options pre-exist, drawn from cross-cultural and anthropological work to the empirically-validated KMDD of Lind (2011a; b). Methods like that of the KMDD $^{\circledR}$ satisfy the ethical imperative of democratic respect and valuation of each and all for their individual contributions to the group, no matter how divergent. This is a space where emergent understanding of our unified wholeness is not only imaginable but can effectively be undertaken with proper guidance. The tools are existing if not yet widespread.

In such a discourse, a culture of difference does not bring animosity but rather awe and curiosity, and a hunger not only for new solutions, but also for process and for relationship building. In the case of posthuman and animal rights concerns, we need not all attempt to "speak" directly with animals, or, non-verbal beings, but we ought to respect them for their intrinsic, noninstrumental qualities. There are those who have undertaken efforts to translate the worlds of those with other languages and ways to us. Not all of us have developed these sensitivities, capabilities, or are equipped with this appreciative perceptive hardware, at least to this extent. Nonetheless, certain 
humans (see: Grandin 2009) give convincing reports of cross-species insight, and they ought to be accounted for in terms of their empirical value and meanings of the interpretive and actual experiences themselves. Moreover, we all deserve the possibility of obtaining access to these possibilities through democratized flows of information in the attempts to communicate meaning. Knowledge may come of this, or, only experience. But within posthumanistic reasoning and relating content is not enforced or drilled down the pipeline of communication. Directness is an asset, as each being, as they are capable, configures their own internal moral codes and understandings, sets of meanings and holds these up for all to see, to examine how they overlap and diverge.

Sociobiological or evolutionary accounts of empirical information and their verification in the systematic enterprise of scientific inquiry is not to be discarded in posthumanistic praxis, as certain strands of postmodernism would contend. Rather, the body of accumulated empirical evidence ought to be turned over and discussed within the spirit of critical inquiry, with as many reasoned interpretations as possible. To have scientific investigation conceptualized, guided, derived, and interpreted from privileged subgroups (see: Ferrando 2012, for more on posthumanisms' methodologies) limits our collective acquisition of knowledge. As cognitive complexity is shown to increase in light of varied experiential exposure, and is exhibited by those of lowered social status or social power (see: Foels and Pappas 2004), balanced diversity again is shown to be an asset. Hence, the need for organizing paradigms and collaborative, communicative efforts yielded through difficult conversations and processual encounters in designed spaces.

\section{Moral Capacities and Inclusive Deliberative Processes}

In times where being considered to be moral is to be rigid and nonpersuadable is to gravely conflate obstinacy with moral integrity. More importantly, a coherent dynamic internal working state of principled moral groundings put into deliberative practice, demonstrates moral judgment competence 27 . Moral orientations and emotions, while acknowledged, do not take the reigns of a morally-adept posthuman ethical system in which individuals are equipped with capacities and capabilities acquired over time through deliberative encounters with diverse and similar agentic beings, characterized by ultimate respect.

It is key to bear in mind the signifiers of being "flexible" and "open" in heart and mind. Rigidity of thought is more than just a turn of phrase: it precludes the ability to be open to that beyond one's interpretation and such cognitive inflexibility and intolerance of uncertainty is tied to dogma and

${ }^{27}$ As defined by Kohlberg and Lind. 
dangerous rhetoric. Linear reductionist zero-sum orientations and ways of interpreting the world, apart from being proven illogical and non-adaptive for complex ecologies have further been bound up with ultimately damaging normative prescriptive non-negotiating means in everything from international relations to economics ${ }^{28}$ to interpersonal relationships (see: MacPherson 1962). Moreover, from a systems-science perspective, they are largely unable to capture the complexity of ecosocial worlds.

Although "altruistic utilitarianism" and social value theory proponents would protest, we have as of yet no absolute set of algorithms or procedural ethics for which to readily apply to a dynamic changing world to yield a maximal coefficient of well being. The complexity is simply too large. However, through guided discussion and dialogue, Lind has been able to converge on a coefficient for interpreting ethical ability or moral judgment competence. Here, a normative overlay might be viewed as a potential hindrance but, not surprisingly, individuals seem to naturally ascend normative scores within trained environments. This is not inconsequential. Indeed, whether one considers studies of human values or the resounding success of international citizen-driven grassroots campaigning 29 , it seems that despite vast cultural differences, gender, ethnicity, and respective sociohistorical contexts, humanity as a whole desires and values certain things like justice, freedom, protection from harm, respect for the environment, and absence of cruelty.

That is not to invocate a blind abductive/retroductive leap and say that because the majority wills it, it is good (argumentum ad populum). Nevertheless, these values may represent an adaptive countering force to hierarchy and inequality-enhancing neoliberal doctrines pushing the wholesale homogenization of "knowledge", "education", "technology", and "finance" through the master rhetoric of inevitable unbridled "Globalization", thereby foreclosing public discussion of biopolitical and environmental issues. Such grounds include evolutionary science's assimilation into relativistic understandings of morality and its bases (see: Teehan \& DiCarlo 2004, on the naturalistic fallacy). This debate and more shall be re-opened, ripe for discussion within posthumanistic praxis.

If we were to become active multi-authored narrative constructors, codesigners of our bodies, brains, minds, and ecosocial worlds, which environments might we seek out? Who amongst us would engage in such a process of imagination, construction? Indeed, this process of visioning has already followed the contours of entrenched socio-cultural privilege (including totalizing rhetorics and financial engrossment of what is best described as technocratic multi-national regimes), which is clearly of great consequence for how we would relate and traverse within and across our

${ }^{28}$ See New Economics Foundation's publications: www.neweconomics.org

${ }^{29}$ See Avaaz.org, 350.org, etc. 
group memberships and ecological boundaries. How can we come together to "horizontalize" this process of posthumanistic praxis in reaching toward deep democracy for our shared ecology, as differentially or commonly defined, disparately and collaboratively, by beings being and becoming themselves. This all the more underscores the need for the re-defining of rights for beings, whether human, as currently defined in this socio-historical slice of time and space, or for the post- or transhuman, of tomorrow. Here, pluralistic integration and complexity systems-science provide interpretative tools (e.g., downward causation, emergent phenomenon analyses) toward such ends.

All of us value certain things over others in the social world and we possess unique moral profiles in relation these rankings. This proposition locates the critical ability to determine for oneself what a good life might consist of, to determine right and wrong in the real world, and such moral choices are routinely encountered and made in the day-to-day. Negotiating possible collective and individual requirements and ethical imperatives in complex ecologies is an immensely difficult task. Still, we know some things and theoretical insight and research has borne out the success of democratic discussion across diverse ecologies (Lind 2011a).

Lind's analogous inoculation of moral dilemmatic issues in coconstructed discursive spaces engenders deeply embedded and embodied experiential learning. Which qualities would such discursive spaces possess for the attainment and achievement of posthuman ethics and moralities? Could we picture ourselves in virtual dialogue with non-human species? Could we find ways to situate the ecological continuum through representatives extending past the purview of environmental rights lawyers and "special interest" groups? Could we find ways to embed opportunities for developing moral competence in all realms of life, though especially in relation to knowledge of the ecological continuum? What for those indigenous communities and traditions who have acted as stewards and companions of non-human species for millennia? And what for those who do not find standard idealized verbal face-to-face communication possible or accommodating? A fully inclusive discursive space must be provided not in some far-off futuristic world but in the here and now, as already there are and would be those left out of the re-defining of what it is to be worthy of life and the rights attached to its boundaries. An equalizing moralistic discussion and multiple authorship around rights for life forces is a foundational base of posthumans living together in harmonious concert. The very enactment of posthumanism as praxis paves ways toward the most deeply "posthumane" moral relating: an actualizing of a rich and varied direct inclusive deliberative process $^{30}$

30 See Fishkin's deliberative process criteria (information, substantive balance, diversity, conscientiousness, equal consideration). 


\section{Practicing Posthumanism For Ecological Justice}

Posthumanism, then, is a praxis, a frame of mind, a way of becoming or developing; it is collaborative, pluralistic, integrative whilst drawing out discrepancies and non-compatibility, and seeks to create. It represents learning in heart and mind through collective discourse of human and ecological ideals, and is so a moralized field. To practice posthumanism is to "synergize", to enter into a "becoming-with" together (Haraway 2008), and where nothing is prefigured in affirmative emergent eco-philosophy (Braidotti 2013). Posthumanism strivings are achievable through moral democratic climates of non-coercion and safety for exploration of all areas of the moral domain, thus setting up space and creating a place for each and every entity, for genuine sustainable and just political processes, solutions, and relationships. It remains to be seen in which realms the defining of the posthuman era will be contested, and which politicized spaces, policies, and practices will be represented. So too, progressive ecologically-grounded policies such as lifelong education, mind-body integrative healthcare support, and basic income guarantees might spur positive feedback loops for potentiating emergent socio-cultural environmental change.

Posthumanism represents an energizing potential for deep democracy in our ecological continuum, a sustainable environmental ethical system (Dereniowska, Matzke 2014), and supplements a call to move into a deliberative process before we hit apocalyptic climatogenic and cultural clashes head on. Millennia-old hierarchy-attenuating values of universalism, harmony with nature, benevolence, and self-direction, of which the majority of the world's human inhabitants rank as most important, over and above power, rank, and exploitative ruining of and ruling over earth and its entities ${ }^{31}$, harbours a harmonious way of existence, of becoming together, of symbiotic synergizing and survival, of co-emergence and flourishing, manifesting in a fully inclusive and just ecosystem.

\section{References}

Alexander, S. 1920. Space, Time, and Deity: The Gifford Lectures at Glasgow, 1916-1918. London: Macmillan \& Co.

Arendt, H. 1958. The Origins of Totalitarianism. Cleveland: The World Publishing Company.

Arisaka, Y. 2001. "The Ontological Co-Emergence of Self and Other in Japanese Philosophy". Journal of Consciousness Studies 8(5-7): 197-208.

${ }^{31}$ See Shalom Schwartz's work on human values. 
Åsberg, C. 2013. "The Timely Ethics of Posthumanist Gender Studies." Feministische Studien 31(1): 7-12.

Baxi, U. 2009. Human Rights in a Posthuman World: Critical Essays. Oxford: Oxford University Press.

Bhaskar, J. 1993. Dialectic: The Pulse of Freedom (Classical Texts in Critical Realism). London: Routledge.

Bloom, A. 1975. "Justice: John Rawls vs. The Tradition of Political Philosophy." American Political Science Review 69(02): 648-662.

Braidotti, R. 2013. The Posthuman. London: Bloomsbury.

Buizer, M., Arts, B., \& Kok, K. 2011. “Governance, Scale And The Environment: The Importance of Recognizing Knowledge Claims In Transdisciplinary Arenas." Ecology and Society 16: 1-18.

Dereniowska, M. \& Matzke, J. 2014. "Interdisciplinary Foundations for Environmental and Sustainability Ethics: An Introduction." Ethics in Progress 5(1): 07-32.

De Waal, F. 2009. Primates and Philosophers: How Morality Evolved. Princeton: Princeton University Press.

Dewey, J. 1916. Democracy and Education. New York: The Macmillan Company.

Docherty, T. 2011. For the University: Democracy and the Future of the Institution. New York: Bloomsbury Academic.

Dutton, D.G. 2007. The Psychology of Genocide, Massacres, and Extreme Violence: Why "Normal" People Come to Commit Atrocities. Westport/London: Praeger Security International.

Eden, A.H., Moor, J.H., Søraker, J., \& Steinhart, E. (eds.) 2012. Singularity Hypotheses: A Scientific and Philosophical Assessment. Berlin: Springer.

Ferrando, F.. 2012. "Towards a Posthumanist Methodology. A Statement." Frame Journal For Literary Studies 25: 9-18.

Fishkin, J. 2009. When the People Speak: Deliberative Democracy and Public Consultation. Oxford: Oxford University Press.

Flender, C. 2011. "Quantum Phenomenology and Dynamic Co-Emergence". In D. Song et al. (eds.), Quantum Interaction. Springer Berlin: Heidelberg.

Foels, R. \& Pappas, C. J. 2004. "Learning and Unlearning Myths We Are Taught: Gender and Social Dominance Orientation." Sex Roles 50: 743-757

Gilens, M. \& Page, B.I. 2014. "Testing Theories of American Politics: Elites, Interest Groups, and Average Citizens." American Political Science Association 12(3): 564-581.

Goldstein, J. 1999. "Emergence as a Construct: History and Issues". Emergence 1(1): 49-72.

Goldstein, J. 2004. "Why Complexity and Epistemology?" E:CO 6(3): 2-3.

Gottlieb, G. 2002 [1992]. Individual Development and Evolution: The Genesis of Novel Behavior. New York: Oxford University Press. 
Grandin, T. \& Johnson, C. 2009. Animals In Translation: Using The Mysteries Of Autism To Decode Animal Behavior. Albany, NY: SUNY Press.

Haraway, D. 1991. A Cyborg Manifesto: Science, Technology, and SocialistFeminism in the Late Twentieth Century. Simians, Cyborgs, and Women: The Reinvention of Nature. New York, NY: Routledge.

Hayles, N. K. 1999. How We Became Posthuman: Virtual Bodies In Cybernetics, Literature, And Informatics. Chicago, IL: University Of Chicago Press.

Holling, C. S. 2004. "Understanding The Complexity Of Economic, Ecological, And Social Systems." Ecosystems 4(5): 390-405.

Jung, C. G. 1969. (1936). The Archetypes of the Collective Unconscious: Vol. 9. The Collective Works of C. G. Jung. Princeton: Princeton University Press.

Kim, J. 1992. "Downward Causation in Emergentism and Nonreductive Physicalism." In A. Beckermann, H. Flohr, \& J. Kim (eds.), Emergence or Reduction? Prospects for Nonreductive Physicalism. Berlin: De Gruyter: 119-138

Kohlberg, L. 1981. "The Meaning And Measurement Of Moral Judgment". In idem (ed.), Essays On Moral Development, Vol. II: The Psychology of Moral Development. San Francisco, CA: Harper \& Row.

Lind, G. 2011a. "Moral Education: Building On Ideals And Fostering Competencies." Contemporary Issues in Education 2(1): 45-59.

Lind, G. 2011b. "Moral Competence and the Democratic Way of Living." European Journal of Psychology 7: 569 - 596.

MacPherson, C. B. 1962. The Political Theory of Possessive Individualism. Oxford: Clarendon Press.

Manson, S. M. 2008. "Does Scale Exist? An Epistemological Scale Continuum for Complex Human-Environment Systems." Geoforum 39(2): 776-788.

McFarland, S., Webb, M., \& Brown, D. 2012. "All Humanity Is in My Group: A Measure and Studies of Identification With All Humanity." Journal of personality and social psychology 103(5): 830-853.

Mikhail, J. 2007. "Universal Moral Grammar: Theory, Evidence and the Future." Trends in Cognitive Sciences 11(4): 143-152.

Mitchell, S. 2004. "Why Integrative Pluralism?". E:CO Special Double Issue 6: 81-91.

Morrill, C. \& Owen-Smith, J. 2002. "The Emergence of Environmental Conflict Resolution: Subversive Stories and the Construction of Collective Action Frames and Organizational Fields." In A. Hoffman \& M. Ventresca (eds.), Organizations, Policy, and the Natural Environment: Institutional and Strategic Perspectives. Stanford: Stanford University Press.

Morton, T. 2012. The Ecological Thought. Cambridge, MA: Harvard University Press. 
Nichols, S. 1988. "The Posthuman Manifesto." Games Monthly Magazine. URL: http://www.posthuman.org/page2.html.

Pettman, D. 2011. Human Error: Species--Being and Media Machines. Minneapolis: University of Minnesota Press.

Randrup, A. A. 2004. "Animal Mind as Approached by the Transpersonal Notion of Collective Conscious Experience". Transpersonal Studies 23: 32-45.

Sayer, A. 2011. Why Things Matter To People: Social Science, Values And Ethical Life. Cambridge: Cambridge University Press.

Sedgwick, E. K. 1990. Epistemology of the Closet. Berkeley: University of California Press.

Snaza, N., Appelbaum, P., Bayne, S., Morris, M., Rotas, N., Sandlin, J., \& Weaver, J. (2014). "Toward a Posthumanist Education". Journal of Curriculum Theorizing 30(2): 39-55.

Starratt, R. 2009. "A Continuing Leadership Agenda." In P. Jenlink (ed.),Dewey's Democracy and Education Revisited: Contemporary Discourses for Democratic Education and Leadership. Maryland: Rowman \& Littleman Education.

Taleb, N. N. 2010. The Black Swan: The Impact of the Highly Improbable. New York: Random House Trade.

Teehan, J. \& DiCarlo, Ch. 2004. "On the Naturalistic Fallacy: a Conceptual Basis for Evolutionary Ethics." Evolutionary Psychology 2: 32-46.

Wilson, J. 1993. The Moral Sense. New York: The Free Press.

Witherington, D. 2007. "The Dynamic Systems Approach as Metatheory for Developmental Psychology". Human Development 50(2-3): 127-153.

Wolfe, C. 2010. What Is Posthumanism?. Minneapolis: University of Minnesota Press. 


\title{
Aiden Sisler (Berlin)
}

\section{'Co-Emergence' In Ecological Continuum: Cultivating Democratic Capacities Through Posthumanism as Praxis}

\begin{abstract}
In this piece I argue for posthumanism-based deliberation and education toward just global ecologies. I propose posthumanism's nonanthropocentric ethical approach and conceptual framework enables a processual multiperspectival account of rich, variegated bionetworks and their organic and inorganic materials' interrelationships and interdependencies. Among reciprocal studies and methodologies, I consider Mitchell's (2004) integrative pluralism in tandem with a developmental systems paradigm of co-emergence to acknowledge the dynamic epistemological continuum of complex ecologies. In terms of specific embedded learning experiences, I briefly discuss Lind's Konstanz Method of Dilemma Discussion (KMDD) ${ }^{\circledR}$ as one specific approach in which to cultivate democratic capacities whilst embracing the destabilizing-stabilizing tendencies of posthumanistic praxis for inclusive flourishing.
\end{abstract}

Keywords: Posthumanism, ecological continuum, education, democracy, integrative pluralism, complexity, emergence

Ethics in Progress (ISSN 2084-9257). Vol. 6 (2015). No. 1, pp. 119-139.

doi: 10.14746/eip.2015.1.10 